\title{
Psychiatry vs. Antipsychiatry: Facts set against Protests
}

Saeed Shoja Shafti

Full Professor of Psychiatry University of Social Welfare and Rehabilitation Sciences (USWR) Razi Psychiatric Hospital Tehran - Iran Corresponding Author: Saeed Shoja Shafti, Full Professor of Psychiatry University of Social Welfare and Rehabilitation Sciences (USWR) Razi Psychiatric Hospital Tehran - Iran

Received date: July 12, 2021; Accepted date: September 02, 2021; Published date: September 10,2021

Citation: Saeed Shoja Shafti. (2021) Psychiatry vs. Antipsychiatry: Facts set against Protests. J. Neuroscience and Neurological Surgery. 9(4); DOI:10.31579/2578-8868/191

Copyrighst: (C) 2021 Saeed Shoja Shafti, This is an open-access article distributed under the terms of The Creative Commons Attribution License, which permits unrestricted use, distribution, and reproduction in any medium, provided the original author and source are credited

\begin{abstract}
Psychiatry is, indeed, basically similar to the rest of medicine. It is based upon making reliable diagnoses and applying evidence - based treatments that have success rates comparable with those used in other specialties. Psychiatric syndromes may be defined as disorders that are conventionally treated with treatments used by psychiatrists. The illnesses in which psychiatrists have developed proficiency have tended to be those that either manifest with disordered psychological functioning (thinking, perception, emotion, and memory) or those which have no obviously established organic basis. However, scientific developments are showing us that these so - called psychological ailments are linked with abnormalities of the brain, just as so - called medical illnesses are deeply affected by psychological factors. Modern psychiatry is an evolving field that is becoming less hospital based, more evidence based, and more neuroscience based. Nonetheless, during the last decades, random antipsychiatry attitudes have amalgamated and turned into a conjectural effort, which has a humanistic appearance, too. On the other hand, publicized criticisms by some associates, including known psychiatrists or psychotherapists, have, radically, stirred and reinforced the movement. Anyway, though various criticisms or worries about psychiatry, either as a subdivision in science or as a clinical practice in medicine are understandable due to existing scientific or diagnostic deficits, anti-psychiatry stance, which comprises many historical exaggerations based on happenings and primitive conditions from a century ago, may help to keep us rigorous and honest about what we do and inspiring us to insistently seek better diagnostic prototypes and management standards. In the present article, the said antagonism, in addition to the existing facts and expected responsibilities of psychiatry has been discussed concisely.
\end{abstract}

Key-words: psychiatry; antipsychiatry movement; psychiatric diagnosis; psychiatric disorder; mental illness; mental health; political abuse of psychiatry

\section{Introduction}

Psychiatry is, indeed, basically similar to the rest of medicine: it is based upon making reliable diagnoses and applying evidence - based treatments that have success rates comparable with those used in other specialties [1]. Most patients with psychiatric disease are not mad and most are treated in primary care. Nor are psychiatric patients a breed apart, since psychiatric diagnoses are common in medical patients. Psychiatric syndromes may be defined as disorders that are conventionally treated with treatments used by psychiatrists, just as surgical conditions are those, which are treated by surgery. The specialty designation does not show an intense difference in the disease or type of patient. In fact it can change as new treatments are developed [1]. For example, peptic ulcer moved from being a principally surgical disease to a medical condition once effective drug treatments were developed. Also, conditions such as dementia may move between psychiatry and neurology. The illnesses in which psychiatrists have developed expertise have tended to be those that either manifest with disordered psychological functioning (thinking, perception, emotion, and memory) or those which have no obviously established organic basis. However, scientific developments are showing us that these so - called psychological ailments are linked with abnormalities of the brain, just as so - called medical disorders are deeply affected by psychological factors [1]. Accordingly, the delineation between psychiatry and the rest of medicine can increasingly be seen as only a matter of convenience and convention. Modern psychiatry is an evolving field that is becoming less hospital based, more evidence based, and more neuroscience based. Studying psychiatry is worthwhile for all trainee doctors, and other health experts, because its skills, knowledge, and approaches are applicable to every branch of medicine [1]. But during the last decades, random antipsychiatry attitudes have amalgamated and turned into a conjectural effort, which has a humanistic appearance, too. On the other hand, publicized criticisms by some associates, including known psychiatrists or psychotherapists, have, radically, stirred and reinforced the aforementioned movement. In the present article, the said antagonism, in addition to the existing facts and expected responsibilities of psychiatry has been discussed concisely.

\section{Background:}

\section{1- History of Psychiatry in a Few Words:}

Across the millennia there have been lots of accounts of melancholy and deluded patients [2]. While psychiatric disorder has always been known as medical in nature, psychiatry as a field and the concept of dedicated mental hospitals raised from the late 18th century, developing first in Italy and then in France [3]. Moreover, before the late 19th century, there was 
no such thing as private practice psychiatry. Before that, ambulatory patients were seen in private practice by neurologists or general practitioners. Because the intellectual content of this growing fledgling field was tremendously organic, at the start, psychiatry had a profound physical orientation. The brain was seen as the base of diseases of the mind, and managements addressed the brain and the body en bloc. Also, studies of inheritance became the main technique of biological psychiatry. Intrinsic to organic outlooks was the postulation that illnesses were caused by the nerves. Beneath the level of frank "insanity," or "madness," anxiety, depression, obsessive-compulsive disorder, and

other nonpsychotic diseases were thought nervous in nature [3], and by the late 19th century, psychiatrists, as "nerve doctors," thought that the main cause of psychiatric disease was "heredity." Furthermore, while many believe that psychiatry possessed no pharmacologic treatments before the psychopharmacologic revolution of the 1950s, psychiatry has always had a series of agents, with varying effectiveness for various mental conditions [4]. For example, ethanol (alcohol) and opium were used as a sedative and hypnotic for milder cases of melancholia, cannabis and hashish were helpful in the treatment of psychotic depression, and chloral hydrate or paraldehyde were used for mild depression and anxiety; Anyhow, psychiatry lacked treatments for such major illnesses as schizophrenia, mania, and catatonia [5]. Likewise, though doctorpatient relationship was an informal kind of psychotherapy, formal psychotherapy begins with Hippolyte Bernheim, professor of medicine at the University of Nancy in eastern France, in 1884, when he distinguished between hypnotic suggestion and non-hypnotic suggestion, or a good talking-to. Also, in 1904, Paul Dubois, professor of neuropathology in Berne, Switzerland, proposed "rational psychotherapy," a forerunner of today's cognitive behavioral therapy (CBT). In 1903, Pierre Janet, professor of experimental psychology at the Sorbonne, proposed cathartic therapy for treatment of "psychasthenia". Group psychotherapy, as well, began by Scottish psychiatrist William Alexander Francis Browne, at the Crichton Royal Hospital in Dumfries in 1842, when he encouraged patients to stage amateur theatricals that amounted to a form of "mental therapeutics." "Closely related to group psychotherapy was the "therapeutic community," which birthed in England during the Second World War at the hands of Joshua Bierer and Thomas Main. Furthermore, psychoanalysis, which was introduced by Sigmund Freud, by the 1920s, had become the chief psychotherapy of psychiatry for years [6]. In 1952, the Rhône-Poulenc Laboratories in Paris introduced the first antipsychotic (neuroleptic), chlorpromazine. So, by revolution in psychopharmacology and introduction of antipsychotics, tricyclic

antidepressants, tranquilizers, benzodiazepines, mood stabilizers, selective serotonin reuptake inhibitors, and second-generation antipsychotics, the modern biological psychiatry shaped. The introduction of "Client-Centered Therapy" by Carl Rogers in 1946, "Family therapy" by Nathan Ackerman in 1956, "Cognitive Therapy" by Aaron Beck in 1963, "Interpersonal neurocircuitry, genetic vulnerability, and environmental Psychotherapy" by Gerald Klerman in 1967, and "Dialectical Behaviorexposures [10]. While clinical training and experience are needed to use Therapy" (DBT) by Marsha M Linehan in 1999, completed the said process, diagnostic manuals for determining a diagnosis [11], it should be noted to this point. On the other hand, in the years 1940 to around 1980 anotherthat these diagnostic criteria and their relationships within the trend raised up in psychiatry, namely social and community psychiatry, whichclassification are based on current research and may need to be modified intended to treat patients in the context of the community and not the asylum, as new evidence is gathered by future research both within and across the and supposed that treatment must include the social environment of the patientdomains of proposed disorders. Mental disorders are defined in relation and all his social relationships, and patient must be treated not only as a person to cultural, social, and familial norms and values [12], and the boundaries but as part of a community. So, many social psychiatrists also introduced between normality and pathology vary across cultures for specific types themselves as social improvers, and assumed that poverty and social of behaviors [13]. However, the diagnosis of a mental illness is not equal disruption were the real foundations of psychological symptoms. Finally, in to a need for treatment. Need for treatment is a multifaceted clinical the last quarter of the 19th century, many national medical groups began judgment that takes into consideration symptom severity, symptom demanding that psychiatry be included in the medical core curriculum, which ${ }_{\text {severity (e.g., the presence of suicidal ideation), the patient's distress }}$ created a request for professors of psychiatry and for academic centers for training [2].

\section{2- The Subject of Diagnosis in Psychiatry:}

A mental illness is a disorder characterized by clinically real trouble in a person's reasoning, emotion regulation, or conduct that echoes a dysfunction in the psychological, biological, or developmental processes underlying mental functioning [7]. Psychiatric disorders are generally associated with momentous distress or disability in occupational, social, or other important actions. So, an expectable or socially accepted response to a common stressor or loss, such as the death of a loved one, is not a mental illness. Socially unusual conduct (e.g., religious, political, or sexual) and conflicts that are principally between the person and society are not mental conditions unless the abnormality or conflict results from a dysfunction in the person, as defined above [8]. Well-known classification systems, like Diagnostic and Statistical Manual of Mental Disorders (DSM), by American Psychiatric Association (APA), which is commended for clinical and research use, and International Statistical Health Organization (WHO), which is designed more for epidemiological and administrative works, have categorized mental disorders, through associated criteria, which have been designed to aid more reliable underlying pathological processes is not possible for most mental disorders, it is important to emphasize that the current diagnostic criteria are the best existing portrayal of how mental disorders are expressed and can be recognized by trained clinicians [8]. They have been used by clinicians and researchers from different orientations (biological, ychodynamic, cognitive, behavioral, interpersonal, family/systems), all of whom try for a common language to communicate the important
physiognomies of mental disorders presented by their patients. The information is of value to all professionals associated with various aspects of mental health care, including psychiatrists, other physicians, psychologists, social workers, nurses, counselors, forensic and legal specialists, occupational and rehabilitation therapists, and other health unbiased evaluation of symptom presentations in a variety of clinical situations-inpatient, outpatient, partial hospital, consultation- liaison, inical, private practice, and primary care - as well in general community pidemiological studies of mental disorders. They are also useful for
ollecting and communicating right public health statistics on mental disorder morbidity and mortality rates [9], and should improve clinicians' bility to find diagnoses in a disorder spectrum based on diagnoses of these disorders [7]. Since a complete description of the experts. The criteria are concise and explicit and intended to help an 
(mental pain) associated with the symptom(s), disability related to the patient's symptoms, risks and benefits of existing treatments, and other issues (e.g., psychiatric symptoms complicating other illness) [14]. While the range of genetic/environmental interactions over the course of human development affecting cognitive, emotional and behavioral function is almost limitless, until unquestionable etiological

or pathophysiological mechanisms are recognized to completely confirm specific disorders or disorder continua, the most important standard for the said guidelines will be their clinical utility for the assessment of clinical course and treatment response of people grouped by a given set of diagnostic criteria [15]. Even when diminished control over one's behavior is a feature of the disorder, having the diagnosis in itself does not show that a particular person is (or was) unable to control his or her behavior at a particular time. Such diagnostic guidelines are also used as references for the courts and attorneys in assessing the forensic consequences of mental disorders, though more information is usually required to make legal judgments on such issues as criminal responsibility, eligibility for disability compensation, and competency [7].

\section{3- Antipsychiatry Movement; Roots and Protests:}

In the 1960s, a growing hostility was presented against psychiatry, which held that by involuntary hospitalization, drugging, electroshock, unclear effectiveness of psychiatric treatments and their potential harm, mystification of human problems, forced domination due to an unequal power relationship between doctor and patient, and a highly subjective diagnostic process, psychiatry was playing, in general, a repressive and controlling role in the world [16]. According to them, psychotherapy or taking psychoactive medication was an inherently unnatural and unethical practice, which had shaped by social and political worries rather than concerns about the well-being of patients [17]. While the term "anti-psychiatry" was coined by David Cooper, definition of "mental illness as a myth", also, was introduced by Thomas Szasz [17]. Somewhat Comparable to Christian Scientists and certain Protestant fundamentalists' outlooks, Psychiatrist Thomas Szasz claimed that "mental illness" is an essentially incoherent amalgamation of a medical and a psychological concept. He opposed the use of psychiatry to forcibly detain, treat, or excuse what he saw as simple deviation from societal standards or ethical conduct. Szasz was concerned that such usage weakened personal civil rights and ethical obligation [18]. As stated by Cooper, the political context of psychiatry and its patients had to be emphasized and radically confronted, and warned that the fog of individualized therapeutic language could take away people's ability to realize and meet the bigger social picture [18]. Also, some other psychiatrists, like R D Laing, Theodore Lidz, and Silvano Arieti argued that schizophrenia and psychosis were understandable, and stemmed from injuries to the inner self - inflicted by psychologically invasive schizophrenogenic parents or others. It was sometimes seen as a transformative state involving trying to cope with a sick society [17]. Moreover, Erving Goffman, Gilles Deleuze, Félix Guattari and others criticized the power and role of psychiatry in society, including the use of "total institutions" and the use of models and terms that were seen as stigmatizing [19]. Similarly, psychoanalysts, like Jacques Lacan and Erich Fromm, have been identified as influential scholars, who had pronounced, in the 1940s and 50s, the secular humanistic concern of the coming anti-psychiatry movement
[17]. Behaviorists, as well, argued that mental disorder was a matter of learning not medicine; for example, Hans Eysenck argued that psychiatry "really has no role to play". Likewise, The French sociologist and philosopher Foucault, claimed that psychiatry was primarily a tool of social control, based historically on a "great confinement" of the insane and corporeal castigation and chains, later switched in the moral treatment era for psychological domination and internalized restraint. Michael Galan, too, challenged the psychotherapy establishment in some ways, and stated that "Therapy means change, not adjustment", and advocated, instead, revolutionary politics and reliable community making. An Italian physician, Giorgio Antonucci, also, hypothesized that the "essence of psychiatry lies in an ideology of discrimination" [20]. The anti-psychiatry movement was also being motivated by persons with adverse experiences of psychiatric services, who see themselves as "psychiatric survivors". This included those who felt they had been damaged or abused by psychiatry or who felt that they could have been assisted more by other approaches, including those who have been forcibly (including via physical force) admitted to psychiatric institutions and subjected to obligatory drug or procedures [20]. Furthermore, legal and professional protections, human rights, and disability rights movements, added to antipsychiatry theory and action. On the other hand, while anti-psychiatry came to confront a "biomedical" focus of psychiatry, there was also antagonism to the increasing association between psychiatry and pharmaceutical corporations, which were more and more claimed to have undue, unfair and sneaky impact on psychiatric investigation and practice [20]. According to some activists, the use of psychiatry as an instrument of social control is becoming evident in preventive medicine programs for various mental syndromes [21,22], and psychiatry possesses a built-in capacity for abuse which is greater than in other areas of medicine [23], and various treatments may work in favor of ideological conformity [24,25]. Similarly, Goffman placed psychiatric hospitals in the same category as prisons, concentration camps, orphanages, military organizations, and monasteries, and describes how the institutionalization process socializes people into the role of a good patient, someone 'dull, harmless and inconspicuous' [26]. In conclusion, many of the said disputes have led to the claim that psychiatry is a pseudoscience [27].

\section{Discussion:}

Psychopathology is the systematic study of abnormal experience, cognition, and behavior. Descriptive psychopathology avoids theoretical explanations for theses psychic events: it describes and categorizes the abnormal experiences as recounted by the patient and observed in his behavior. Phenomenology is the study of events, either psychic or physical, without embellishing those events with explanation of cause or function. Descriptive psychopathology therefore includes subjective aspects (phenomenology) and objective aspects (description of behavior). On the other hand, Lewis pointed out that mental illness could be characterized in terms of psychopathology: 'disturbance of part functions as well as general efficiency'. Part functions refer to the different aspects of psychic experience and behavior, like memory, perception, forming beliefs and so on. Thus Lewis saw a disturbance in perception, for example, hallucination, as a reason for establishing a case of mental illness - on psychopathological grounds. Traditionally, symptoms have been divided into these causing suffering and pain (disease) and those causing loss of function (disability). Symptoms are collected into 
constellations that commonly occur together to form the syndromes of mental illness. It is usual to distinct between illness, with a definite onset after normal health, and the lifelong characteristics of mental handicap or personality disorder. Another fundamental distinction usually made by psychiatrists and based ultimately upon psychopathology, is that between psychoses and neuroses. Psychoses are major mental illnesses. They are exceedingly hard to define although they are usually said to be characterized by severe symptoms, such as delusions and hallucinations, and by lack of insight; there is loss of contact with reality. Neurosis is a psychological reaction to acute or continuous perceived stress, expressed in emotion or behavior ultimately inappropriate in dealing with that stress; phenomenological characteristics held in common by neurotic patients include disturbances of self-image, of the experience of relationships and often, bodily symptoms without organic cause [28]. Psychiatry, as one of the latest specialists in medicine, and, likewise, one of its most important fields, due to simultaneous dealing with both persons and families, and a basic multidimensional approach (bio-psycho-social), which makes it more complicated and responsible than other comparable specialties, which have merely corporal outlooks, is the product of integration of sociocultural characteristics of human being and valuable findings of biomedical science. Certainly, such a tool aims to theorize and classify mental disorders as methodical as possible, though it lacks necessary organic indicators. Absence of basic biological measures does not mean that it is a made-up or groundless premise. For instance, while current psychiatry demands ultrastructural causes for its disorders, in comparison with neurologic disorders that are typically due to discernible microscopic or macroscopic lesions, it tries to confirm the categorized mental disorders with a multifactorial attitude, which considers genetic and environmental aspects, from one hand, and phenomenological or descriptive approach, on the other hand. The said maneuvers, which are out of necessity and forced by the circumstances, have made every effort, until now, to compensate a bit the absence of biological origins of mental disorders, which indeed exist. Psychiatric ailments are not made-up complaints, because they create lots of distress, or functional impairment; they are unusual and undesirable conditions that oppose seriously the premorbid and tolerable states. Diagnosis based on interview and Mental Status Examination (MSE), rather than biological discoveries, does not wipe out the necessity of diagnosis per se. On a historical basis, several diagnoses do stand out as enduring, and almost certainly symbolize phenotypes of genuine underlying psychiatric maladies, like Melancholia, which is one of the oldest diagnoses in medicine and goes back to the Ancients. Similarly, disorders like psychotic depression, mania, catatonia, delusional disorders, anxiety disorders, chronic primary psychosis (Schizophrenia), brief reactive psychosis or brief psychotic disorder, bipolar disorder, trauma and its sequels, dementia, and neurosis have had their specific accounts in the last centuries $[2,29]$. The real inquiry in psychiatry is not the reality of mental disorders, but accurateness, completeness, and validity of operational definition, for any specific disorder, and the range of overlapping or discreetness of such definition, for the purpose of differential diagnosis. At present, for accomplishment of such purposes in clinical psychiatry and enhancement of current diagnostic categorizations, like DSM and ICD, up-to-date statistical kits and methodical studies are being implemented to make the existing guidelines more precise, practical and useful. Thus, contemporary psychiatry attempts to confirm its categorizations and managements by application of modern statistical techniques, systematic studies, controlled trials, and reliable psychiatric scales, for enhancing sensitivity of diagnosis and accuracy of treatments, and by application of laboratory exams, electrophysiological assessments, like electroencephalography (EEG), Quantitative EEG (QEEG) Brain Mapping, neuroimaging techniques, like Magnetic resonance imaging (MRI), Functional MRI (fMRI), positron emission tomography (PET), and single-photon-emission tomography (SPECT), try to augment specificity of diagnosis and exclusion of possible medical problems [2]. The said process is the basis of diagnostic changes in consecutive updating of the said classifications; a course, which is not uncommon even in other specialties with clear-cut organic basis. Explanation of psychiatric symptoms or disorders as outdated behavioral strategies or programmed interactive apparatuses for ecological or social adjustments, similar to the concepts of evolutionary psychology, or as the outcome of social disarray and unfairness that is imposed by class struggle, like Marxian philosophies, while interesting and thinkable, are not clinically and commonly problem-solving, at least in short-term, and in many of the existent circumstances. Though they may be worthy subjects for a range of psychotherapeutic interventions or theoretical dialogues, they seem inept for returning the mental relaxation in neurosis, or soundness of reality testing and function in psychosis, quickly. Why quickly? Because in the present complicated sociopolitical conditions, there is no guarantee for acceptable recovery of missing opportunities, broken families, lost prestige, damaged trustworthiness, or self-confidence; namely, roots of psychiatric stigma, which is not enacted by psychiatry or psychiatrist, but is being shaped publically due to individual's unusual manners [30, 31]. Criticizers, who see stigma as the outcome of psychiatric diagnosis and treatment, have realized the causal process backward [32]. Unlike psychiatrists, who are not allowed to show clients' secrets, based on the professional ethics and code of confidentiality, except in legalized circumstances, ordinary people see and appraise neighbors' activities ceaselessly, and are not forbidden with respect to gossips or baseless remarks [32]; also, they are not obliged to close their eyes to impaired self-care, reckless aggression, sexual inconsideration, and careless behavior of any person with mental illness; as like as the families who can not recompense, ceaselessly or hopelessly, the patient's expenses and anticipations during his or her endless unemployment, and endure eternally the burden caused by patient's unbearable conduct [32]. On the other hand, psychiatrist is usually the last doctor, after GPs, family physicians, and, sometimes, faith healers, for referral and help seeking, a gap which is generally enough for formation of stigma before any official psychiatric diagnosis. Normal life demands regular behavior, and regular behavior requires ordinary mentality and judgment; inevitabilities which are totally out of psychiatrist's control, if stay treatment-resistant [33]. Relationship between psychiatrists and mental patients is a professional alliance that is limited to therapeutic managements, and patients' adherence to the recommended treatments. Therefore, it does not have anything to do with power inequality and control, apart from passed over transference or counter-transference difficulties. Nevertheless, such a problem, though is not restricted to psychiatrists, must be discerned and coped proficiently. Therapists, who advocates for merely talking-based therapies, even for very debilitating conditions such as schizophrenia, indeed are not acquainted with psychoses. Psychotherapies are not enough even for neuroses, because, if they were enough even during golden age of psychoanalysis, then no other psychotherapeutic method, psychosocial intervention, or psychotropic medication was necessary to 
be invented or manufactured. On the other hand, a considerable percentage of non-psychotic problems (neuroses), like depression, obsessive-compulsive disorder, post-traumatic stress disorder, or panic disorder, are not basically or properly treatment responsive, and demand a variety of managements. The said condition is worse with respect to psychotic disorders. Also, in psychiatric emergencies, like catatonia and suicide, time can be the matter of life and death, and resorting to supplementary procedures, like electroconvulsive therapy (ECT), is vitally important. Besides, with respect to some psychiatric disorders, like mood disorders, ECT is always the last tool, which is implemented when, in spite of severity of disorder and related dysfunctions, the psychotropic medications fail, or their side effects are not tolerable, or their hazards are more than their benefits. Moreover, the related sessions are being accomplished while the patient has been anesthetized beforehand, and so, no memory is retrievable about the induced seizures, like major surgical operations that are being implemented under general anesthesia. Even in comparison with newer devices, like repeated Transcranial Magnitude Stimulation (rTMS) or Vagal Nerve Stimulation (VNS), ECT is the first choice in lifethreatening or hardy cases. Definitely, every implement, like every medicine, has its specific indications, benefits, and drawbacks, which can be measured only by legally liable experts. Concisely, psychotropic medications, as well, have been manufactured by pharmaceutical corporations for helping or preserving patience and peace in distressful conditions, like antidepressants and anxiolytics, or reducing trouble in destructive circumstances, like mood stabilizers and antipsychotics [34]. Without antipsychotic drugs, deinstitutionalization was only a dream and successes of psychiatric rehabilitation and implementation of community psychiatry was not even thinkable; though the said agendas were not uncomplicated, too, since "deinstitutionalization," which was speeded under the influence of the antipsychiatric ideas, by discharging in-patients to a kind of community care, often turned out to be the care of the streets and in reality they fed the vast ranks of the homeless and the imprisoned [35]. In defining mental health, while it must be considered that "average" is not routinely healthy, and what is healthy sometimes depends on geography, cultural values, historical moment, and the issue of trait or state, mental health is a spectrum that is formulated by function and communication [29] ; namely, mental health can be conceptualized as the capacity to work and to love, maturity, human strengths, successful object relations, subjective well-being, and the capacity for successful adaptation and homeostasis [36], and, so, mental disorder is a consequence of disarray in the said processes. Mental illnesses, are not made-up or unreal myths because, first, each disorder have its specific diagnostic criteria, based on longitudinal, cross-sectional, historical and phenomenological physiognomies, and moreover, the imposed troubles and burden on subjects and relatives, can not be managed by journalistic dialogues or anti-elitist propaganda, and demand specialized care and help, which is asked beseechingly by sufferers, and must be responded conscientiously by psychiatrists [37]. Involuntary hospitalization, as well, is usually based on frequent or serious violation or threat of civil rights of relatives, partners, colleagues, friends, neighbors, or the community, which is petitioned legally and sanctioned by law enforcement agency and courthouse. So, while individual's freedoms are respectful, it does not confirm impairing other's civil liberties, based on subjective judgment of spectators or activists. Though no human being is flawless and the risk of mistake, misuse, radicalism, or conspiracy is not deniable, the real intention is generally and logically defending the dynamic part of society against supposable or real threats, and protecting the patient against self-induced harm or scandal. So, while a psychiatric emergency is defined as a condition in clinical practice that requires immediate intervention to prevent death or serious harm to the patient or another person or to prevent deterioration of the patient's clinical state, involuntary admission involves the question of whether patients are suicidal and thus a danger to themselves or homicidal and thus a danger to others, or possibly so unable to care for themselves that they cannot survive outside [38]. Also, patients have the right to receive the least restrictive means of treatment for the requisite clinical effect.so, restraints and seclusion can be implemented only when a patient creates a risk of harm to self or others and no less restrictive alternative is available, and can only be implemented by a written order from a proper medical official [39]. While the duty to protect patients and endangered third parties should be considered primarily a professional and moral obligation and, only secondarily, a legal duty, psychiatrists who treat violent or potentially violent patients may be sued for failure to control aggressive outpatients and for the discharge of violent inpatients [40]. Hence, Psychiatrists can be sued for failing to protect society from the violent acts of their patients if it was reasonable for the psychiatrist to have known about the patient's violent tendencies and if the psychiatrist could have done something that could have safeguarded the public. While courts and state legislatures have increasingly held psychiatrists to a fictional standard of having to predict the future behavior (dangerousness) of their potentially violent patients, research has consistently demonstrated that psychiatrists cannot predict future violence with any dependable accuracy [41]. On the other hand, psychiatry is not always about confinement (admission) and controlling (treatment); it can be helpful for liberating, too. For example, to be proven guilty of committing a crime, the prosecution must prove beyond a reasonable doubt that the accused person not only committed a prohibited act but also had the requisite mental state or "guilty mind" for the forbidden act [42]. Thus, the insanity defense is used to prove that an individual did not have the necessary mental state for criminal responsibility due to mental illness at the time of the act [42]. Psychiatry, more than any other field of medicine, concerns itself with studying and strengthening the capacities that make humans distinct and that allow people to attach, learn, love, reason, feel, live with one another, and make choices [43]. True ethics ability, robust decision-making skills, and disciplined ethics practices are of special importance for psychiatrists because of their professional responsibility to start treatment to protect a patient or others from harm when necessary - even if it is against the patient's wishes [43], social norms, or prevailing political trends.

\section{Conclusion:}

Respect for autonomy, beneficence, non-maleficence, and justice, are four ethical principles that psychiatrists ought to weigh in their work. At times, they are in conflict, and decisions must be made about how to balance them [27]. It is not deniable that, while anti-psychiatry consists of many historical exaggerations based on events and primitive conditions from a century ago, it may help keep us honest and rigorous about what we do and motivating us to relentlessly seek better diagnostic models and treatment paradigms [16]. Although, many criticisms or worries about psychiatry are understandable, due to existing scientific or diagnostic deficits, its approaches, at this time, are evidence-based, and in line with the systematic studies, and consistent with The 'Declaration of Helsinki 
and Ethical Principles for Medical Research Involving Human Subjects' [44]. Reliability and validity of psychiatric diagnosis, in the absence of firm organic etiology, is based on methodical measurements and interpretations, which can be revised over and over again, by the aid of new discoveries or insights. At the moment, there is no other beneficial alternative for assisting people, who are suffering mental disorder, and are exposed to personal debility, family anarchy, and serious social troubles, like joblessness and dishonor. Therefore, while psychiatry is an evolving science, which is established on historical facts, real conditions, and scientific discoveries, it is a helpful clinical field for differentiation between competency and incompetency, insightfulness and witlessness, usual behavior and anomalous conduct, intact reality testing and impaired truth analysis, unaffected judgment and compromised verdict, fit cognition and disordered intellect, sound planning and superficial setting up, manageable sentiments and incontrollable excitements, fine mindset and thought chaos, common perceptions and scarce sensitivities. Also, psychiatry can reassure concerned people about soundness of their mentality, or filling the deficiency of intuitive relatives by acting out as an informed advisor or expert psychotherapist.

\section{References:}

1- Harrison P, Geddes J, Sharpe M. Lecture Notes: Psychiatry, 10th edition. Blackwell Publishing Ltd. Oxford, 2010.

2- Shorter E. History of Psychiatry In: Sadock BJ, Sadock VA, Ruiz P, eds. Kaplan \& Sadock's Comprehensive Textbook of Psychiatry. 10th ed. Philadelphia: Wolters Kluwer, 2017: 44924516.

3- Engel JW. Early psychiatry at Yale: Milton C Winternitz and the founding of the department of psychiatry and mental hygiene. Yale J Biol Med. 1994; 67(1-2):33-47, 39.

4- Shorter S. A Historical Dictionary of Psychiatry. New York: Oxford University Press; 2005.

5- Cohen RA. Interview. In: Ban TA, ed. An Oral History of Neuropsychopharmacology . I, 194. Brentwood, TN: ACNP; 2011.

6- Lindon JA. Melanie Klein. In: Alexander F, et al., eds. Psychoanalytic Pioneers. New York: Basic Books; 1966:360372, 367.

7- American Psychiatric Association (APA). Diagnostic and Statistical Manual of Mental Disorders. 5th ed. Washington, DC: American Psychiatric Association, 2013: 5-25.

8- Adamowski T, Kiejna A. Classifications of mental disorders from a historical and contemporary perspective. Adv Clin Exp Med 2007; 16(2):189-195.

9- Cooper JE, Sartorius N. A Companion to the Classification of Mental Disorders. Oxford: Oxford University Press; 2013.

10- Maj M, Wolfgang G, López-Ibor JJ, Sartorius N. Psychiatric Diagnosis and Classification. Chichester: John Wiley \& Sons; 2002.

11- Miklowitz DJ, First MB. Specifiers as aids to treatment selection and clinical management in the ICD classification of mood disorders. World Psychiatry 2012; 11(Suppl 1):11-16.

12- Reed GM, Mendonça Correia J, Esparza P, Saxena S, Maj M. The WPA-WHO global survey of psychiatrists' attitudes towards mental disorders classification. World Psychiatry 2011; 10(2):118-131.
13- Vaillant GE. Positive mental health: Is there a cross-cultural definition? World

14- Psychiatry 2012; 11(2): 93.

15- Tyrer P, Reed GM, Crawford MJ. Classification, assessment, prevalence, and effect of personality disorder. Lancet 2015; 385(9969): 717 - 726.

16- Marrero I, Bell M, Dunn LB, Roberts LW. Assessing professionalism and ethics knowledge and skills: Preferences of psychiatry residents. Acad Psychiatry 2013; 37(6): 392 - 397.

17- Nasser M. The rise and fall of anti-psychiatry. Psychiatric Bulletin. 1995; 19 (12): 743 - 746.

18- Norman D. Psychiatry and anti-psychiatry in the United States. In Micale, Mark S.; Porter, Roy (eds.). Discovering the History of Psychiatry. Oxford \& New York: Oxford University Press. 1994: 415 - 444.

19- Rael S. Psychiatry during the Nazi era: ethical lessons for the modern professional. Annals of General Psychiatry 2007; 6 (8): 8.

20- Shoja Shafti S. Psychiatric Stigma in Developing Societies. Biomedical Research and Clinical Reviews 2021; 3 (3):1 - 5.

21- John F. The Man Who Closed the Asylums: Franco Basaglia and the Revolution in Mental Health Care. New York: Verso Books, 2015: 105.

22- Gosden R. Punishing the Patient: How Psychiatrists Misunderstand and Mistreat Schizophrenia. Melbourne: Scribe Publications, 2001: 14.

23- Shoja Shafti S. SET-UP MADNESS: A REVIEW. ASEAN Journal of Psychiatry 2021; 22 (2): 1 - 8.

24- Birley J LT. Political abuse of psychiatry. Acta Psychiatrica Scandinavica 2000; 101 (399): 13 - 15.

25- Shoja Shafti S. Frame-up Psychosis: A Dilemma in the Realm of Forensic Psychiatry. Clinical Psychology and Mental Health Care 2021; 2 (3): 1 - 6.

26- Shoja Shafti S. Diagnostic Review of an Important Criminal Dilemma: Entrapment Madness. Annals of Clinical Cases 2021; 2(2): 37 - 41.

27- Davidson L, Rakfeldt J, Strauss J, at al. The Roots of the Recovery Movement in Psychiatry: Lessons Learned. John Wiley and Sons; 2010: 150.

28- Strebler A, Valentin C. Considering ethics, aesthetics and the dignity of the individual. Cult Med Psychiatry 2014; 38(1): 35 $-59$.

29- Sims A. Symptoms in the mind: an introduction to descriptive psychopathology. Bailiere Tindall, London, 1988.

30- Vaillant GE, Vaillant CO. Normality and mental health. In: Sadock BJ, Sadock

31- VA, Ruiz P, eds. Kaplan \& Sadock's Comprehensive Textbook of Psychiatry.

32- 9th ed. Philadelphia: Lippincott Williams \& Wilkins; 2009: 691.

33- Shoja Shafti S. Stigmatization and Psychiatry: A Local Review. Online Journal of Neurology and Brain Disorders 2021; 5 (2): 456 - 462.

34- Carter R, Shimkets RP, Bornemann TH. Creating and changing public policy to reduce the stigma of mental illness. Psychol Sci Public Interest 2014; 15(2): 35 -36. 
35- Ungar T, Knaak S, Szeto AC. Theoretical and practical considerations for combating mental illness stigma in health care. Community Ment Health J 2016; 52(3): 262 - 271.

36- Pérez-Garín D, Molero F, Bos AE. Internalized mental illness stigma and subjective well-being: the mediating role of psychological well-being. Psychiatry Res 2015; 228: 325 - 331.

37- Sourkes TL. A biochemist in psychiatry: dropping in on the psychopharmacology era. In: Thomas A Ban, et al., eds. Reflections on Twentieth-Century Psychopharmacology. Budapest: Animula; 2004: 291 - 292.

38- Chow WS, Priebe S. Understanding psychiatric institutionalization: A conceptual review. BMC Psychiatry 2013; 13: 169.

39- Prince M, Patel V, Saxena S, et al. No health without mental health - a slogan with substance. Lancet 2007; 370: 859 - 877.

40- Wakefield JC. Misdiagnosing normality: Psychiatry's failure to address the problem of false positive diagnoses of mental disorder in a changing professional environment. J Ment Health 2010; 19 (4): 337.

41- Mrad DF, Watson C. Civil commitment. In: Drogin EY, Dattilio FM, Sadoff RL, Gutheil TG, eds. Handbook of
Forensic Assessment: Psychological and Psychiatric Perspectives. Hoboken, NJ: Wiley; 2011.

42- Wada K, Doering M, Rudnick A. Ethic's education for psychiatry residents. Camb Q Healthc Ethics 2013; 22 (04): 425 -435 .

43- Watson C, Eth S, Leong GB. Clinical-Legal Issues in Psychiatry. In: Sadock BJ, Sadock VA, Ruiz P, eds. Kaplan \& Sadock's Comprehensive Textbook of Psychiatry. 10th ed. Philadelphia: Wolters Kluwer, 2017: 4427 - 4439.

44- Sadock BJ, Sadock VA, Ruiz P, eds. Forensic Psychiatry and Ethics in Psychiatry. Kaplan \& Sadock's Synopsis of Psychiatry. $11^{\text {th }}$ edition. Philadelphia: Lippincott Wolters Kluwer; 2015: 1382 - 1399.

45- Weinstock R, Leong GB, Silva JA. Competence to be executed: an ethical analysis post Panetti. Behav Sci Law 2010; 28: 690 706.

46- Roberts LW. A Clinical Guide to Psychiatric Ethics. Arlington, VA: American Psychiatric Association Publishing; 2016.

47- Medical Association Declaration of Helsinki: ethical principles for medical research involving human subjects. JAMA 2013; 310(20): 2191 - 2194.

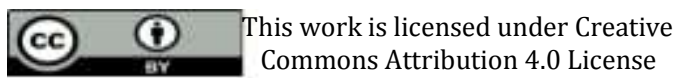

To Submit Your Article Click Here: Submit Manuscript

DOI: $10.31579 / 2578-8868 / 191$
Ready to submit your research? Choose Auctores and benefit from:

* fast, convenient online submission

* rigorous peer review by experienced research in your field

* rapid publication on acceptance

* authors retain copyrights

* unique DOI for all articles

* immediate, unrestricted online access

At Auctores, research is always in progress.

Learn more www.auctoresonline.org/journals/neuroscience-andneurological-surgery 